\title{
Dr. Raúl Etcheverry Barucchi (1909-2014)
}

\author{
Raúl B. Etcheverry, M.D. (1909-2014)
}

Professor Raúl B. Etcheverry, M.D., was a founder of Chilean Hematology back in the 1940's and a practicing physician and teacher until an advanced age. Being a superb clinician, he was admired by his ability to unveil from the most common to the most difficult diagnosis of blood disorders and neoplasms by examining blood smears and cytology samples. He trained in Hematology a large number of physicians and technicians coming from several countries in Latin America as well as from Chile. Besides medicine, he conducted seminal studies to unveil ethnic characteristics of the original inhabitants of Chile identifying blood groups and other genetic markers in mummies and in current living descendants, from Northern and Southern Chile and from Easter Island. He was a prominent scholar that was awarded high titles and distinctions from the University of Chile, the Chilean Academy of Medicine, the Chilean Government, and several hematological societies from Chile and other countries. After 104 years of fruitful life, he passed away leaving a vast number of disciples and admirers.

(Rev Med Chile 2014; 142: 395-397)

Key words: Anthropology, cultural; History of Medicine; Hematology; Teaching.

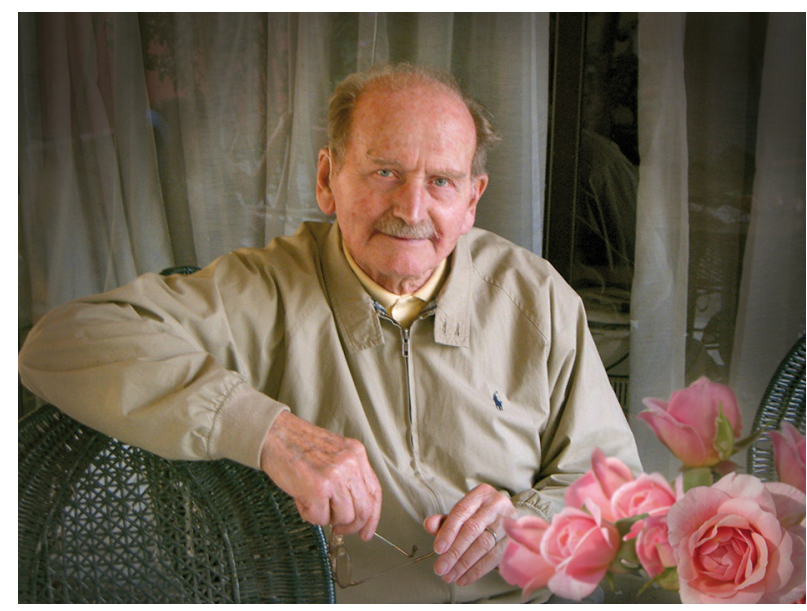

$\mathrm{E}$ 1 Dr. Raúl Etcheverry Barucchi nació el 9 de mayo de 1909 en la ciudad de Córdoba, Argentina, con ancestros vascos, por línea paterna, e italianos por la materna. Siendo un niño, su familia se trasladó a Santiago de Chile y don Raúl conservó su nacionalidad argentina, primero por respeto a su padre y después por modestia. Refiriéndose a la posibilidad de nacionalizarse chileno, dijo: "Nunca he pedido nada para mí, si me la dan la recibiría honrado". Años después el Parlamento chileno le concedió "por gracia" la nacionalidad chilena, con el derecho a conservar la doble nacionalidad.

Don Raúl estudió en el Instituto Nacional y en la Facultad de Medicina de la Universidad de Chile. Llegó al Hospital del Salvador en 1933 como alumno de los últimos años de la carrera, siendo destinado a la Sala San Roque, atendida por el doctor Hernán Alessandri, quien pronto sería Jefe del Servicio, Profesor de Medicina y uno de los clínicos más destacados del Siglo 20.

Don Raúl Etcheverry terminó sus estudios de medicina con una tesis sobre "Alteraciones del hemograma y del líquido cefalorraquídeo en el tifus exantemático", inspirada en su atención de pacientes hospitalizados durante un brote epidémico de esta enfermedad. Recibió el título de Médico Cirujano el 26 de julio de 1934, y se incorporó al Servicio de Medicina del hospital que sería como su casa durante su vida profesional. 
El Dr. Alessandri impulsó a su joven ayudante para que creara la especialidad de hematología. Don Raúl nos dijo incontables veces que "había sido encadenado al mesón del laboratorio, frente a un microscopio", pero los que conocimos su pasión por esa especialidad dudamos que haya sido así, porque se fue convirtiendo en el artífice máximo que ha tenido la medicina de nuestro país, en la interpretación de los exámenes hematológicos y su significado clínico. Casi toda su carrera la hizo al lado de su jefe e inspirador, el doctor Alessandri, con quien se creó un estrecho vínculo. Primero fue su ayudante, luego su amigo y, en los años postreros de la vida del doctor Alessandri, don Raúl fue, además, un confidente fraternal.

Conocí a don Raúl en marzo de 1957, cuando llegué en $4^{\circ}$ año de Medicina al Hospital del Salvador y desde entonces he sido uno de los numerosísimos testigos de su vida profesional.

Don Raúl estaba desde las 7 de la mañana hasta muy tarde en el día, sentado frente a su mesón de laboratorio con un microscopio. En ese sitio de trabajo resolvía consultas, examinaba muestras de diversa índole, pero siempre preguntaba los antecedentes clínicos de quien estaba examinando, para luego ir a donde estuviera el paciente: a una sala si estaba hospitalizado, al policlínico si era ambulatorio, a su propia consulta o a la casa del paciente, si era privado. Allí lo interrogaba, lo examinaba, luego opinaba y aconsejaba o decidía lo que había que hacer. Sus diagnósticos eran tan acertados como para despertar un gran respeto de sus pares.

Dotado de una memoria prodigiosa, podía darse el lujo de no respetar normas de orden propias del común de los mortales. Justificaba el desorden patético de su mesón de laboratorio diciendo: "Yo tengo todo aquí (tocándose los bolsillos del delantal)... o acá" (tocándose la cabeza). Efectivamente, los bolsillos de sus delantales eran como pequeñas mochilas, repletas con láminas de vidrio envueltas con papelitos en los que anotaba los datos del paciente, su ubicación y, después, frente al microscopio, en el reverso del papelito anotaba de puño y letra la descripción de lo que había observado.

Jamás conocí alguien que pudiera recordar a tantas personas, en tantas circunstancias, con tantas características, como lo consiguió él. En muchas de las reuniones clínicas semanales, don Raúl nos señaló en quién había visto ese cuadro clínico, cuándo, dónde y qué paso con él o ella.

Además de su sabiduría, don Raúl destacó por su generosidad. Formó a muchos discípulos, hematólogos de adultos y de niños. Aconsejó a todos los médicos que nos acercábamos a pedirle ayuda, no sólo con nuestros enfermos del hospital sino también con pacientes privados. Atendió graciosamente a muchos médicos y sus familiares, de múltiples especialidades y de todo el país. En la puerta de su laboratorio del hospital había frecuentemente personas esperando la oportunidad de hablar con él para recibir su opinión, un consejo, una receta, una palabra de aliento.

En los comienzos de su carrera, colaboró estrechamente con el doctor Gabriel Gasic, profesor de Biología en la Facultad de Medicina de la Universidad de Chile y destacado investigador en cáncer. Como pionero de la Hematología en Chile, compartió méritos con los Dres Camilo Larraín, Germán Ducach y, en aspectos clínicos, con los Dres. Rodolfo Armas Cruz y Hernán Alessandri (su maestro, con quien hizo ensayos iniciales para el tratamiento de la anemia perniciosa con inyecciones de vitamina B12). Tuvo discípulos y colaboradores muy cercanos y distinguidos, como los Dres. Carlos Guzmán, Carlos Regonesi, Alberto Daiber. Fue el primero en Chile en aplicar el citodiagnóstico para algunos tipos de neoplasias malignas y el primero en practicar transfusiones de sangre en su hospital, en una época heroica (1936) en que se realizaban "de persona a persona". Yendo más allá de la medicina, impulsó con entusiasmo la tarea de investigar los orígenes étnicos de nuestra población, escudriñando características de los grupos sanguíneos y otros marcadores genéticos en momias y en descendientes de los primeros pobladores de nuestro país, para lo cual hizo esforzados viajes y exploraciones en gran parte del territorio nacional, incluso en la legendaria Rapa Nui. Su sabiduría recibió un reconocimiento internacional, ilustrado por su rol en la fundación de numerosas sociedades científicas en países de Latinoamérica, y en la formación de hematólogos para Chile, Argentina, Costa Rica, Panamá, Perú, Uruguay.

La Sociedad Médica de Santiago, a la que había ingresado apenas graduado como médico y en la que participó en incontables actividades científicas, lo nombró Socio Honorario y posteriormente le otorgó el título de "Maestro de la Medicina Interna". La Sociedad Chilena de Hematología, de la 
que había sido fundador, lo nombró "Padre de la Hematología Chilena" (1976). Recibió distinciones como "Protomaestro de la Hematología" en Mendoza, Argentina (1991), "Decano de los Hematólogos Activos de Latinoamérica" en Cartagena de Indias, Colombia (1992), Miembro Emérito de la Sociedad Internacional de Hematología, y Miembro Fundador de la Sociedad Internacional de Bioantropología (Bélgica). La Universidad de Chile le dio categoría de Profesor Titular de Medicina y posteriormente lo nombró Profesor Emérito. Fue reconocido como Miembro Emérito del Colegio Médico de Chile, Médico Distinguido del Ministerio de Salud y en 1990 recibió la Condecoración Presidente de la República con la Orden de la Cruz del Sur, grado Gran Cruz.

En 1975 ingresó a la Academia Chilena de Medicina del Instituto de Chile como Miembro Correspondiente, dictando una conferencia sobre "Hematología geográfica, genética sanguínea y razas humanas" y en 1981 fue incorporado en la categoría de Miembro de Número, dictando una conferencia sobre "Linfocitos e inmunidad", para ocupar el sillón que estaba vacante desde el fallecimiento de su querido maestro y amigo, don Hernán Alessandri.

Don Raúl ejerció la medicina durante casi 80 años, vivenciando su progreso científico y tecnológico. Hizo sus primeros exámenes con un microscopio monocular; después de muchos años consiguió uno binocular, pero pasaron décadas en que para poder mostrar a otra persona lo que veía en el microscopio tenía que inclinarse a un costado. En 1980, cuando falleció el Profesor Alessandri, se formó la Fundación Social y Educativa Doctor Hernán Alessandri Rodríguez. Una de las primeras obras de esta Fundación fue comprar un microscopio múltiple que permite la visión simultánea por varios observadores. Ese fue un regalo para don Raúl, en memoria de su querido maestro.

Además de médico, el doctor Etcheverry fue poeta. Alguna vez escribió: "Así como siempre hay veinte años en un rincón del corazón, el espíritu de la juventud no muere, solo duerme en el subconsciente, para despertar y aflorar en algunas circunstancias de la vida". Pocas personas hemos conocido en que el espíritu de la juventud haya estado presente por tantos años.

Un fragmento de uno de sus poemas dice:

“QQué es el alma, me preguntas niña mía? ¿Quieres que te responda el médico o el poeta? Porque el alma, aún un misterio en psiquiatría, es una sintesis de todo lo bello en poesía."

En marzo de 2014, semanas antes de cumplir ciento cinco años de edad, falleció en Santiago de Chile un médico excepcional, sabio, poeta y maestro inolvidable.

Dr. Humberto Reyes B. 